\title{
Anatomic Anterior Cruciate Ligament Reconstruction using Quadriceps Graft
}

\author{
Diaaeldin Youssef* and Mohamed Goda \\ Department of Orthopedics, Banha University, Egypt
}

Submission: March 20, 2018; Published: April 04, 2018

*Corresponding author: : Diaaeldin Youssef, Department of orthopedics, Banha University, Egypt, Email: deyaayoussef@hotmail.com

\begin{abstract}
Surgical reconstruction of the anterior cruciate ligament (ACL) is indicated in the ACL-deficient knee with symptomatic instability and multiple ligaments injuries. In the present study, we describe the clinical results of quadriceps tendon autograft for ACL reconstruction. From 2015 to 2018, the graft has been used in 20 patients. Twenty patients with complete final follow-up for 2 years were analyzed. Finally; 20 patients $(100 \%)$ were assessed as normal or nearly normal rating by IKDC guideline. Sixteen patients $(80 \%)$ had less than $10 \mathrm{~mm}$ difference in thigh girth between their reconstructed and normal limbs. Nineteen (95\%) patients could achieve recovery of the extensor and flexor muscle strength in the reconstructed knee to $80 \%$ or more of normal knee strength.

A statistically significant difference exists in thigh girth difference, extensor strength ratio, and flexor strength ratio before and after reconstruction. Tunnel expansion with more than $1 \mathrm{~mm}$ was identified in $2(10 \%)$ tibial tunnels. Our study revealed satisfactory clinical subjective and objective results at 2 years follow-up. Quadriceps tendon autograft has the advantage of being self-available, relatively easier arthroscopic technique, and having a suitable size, making it an acceptable graft choice for ACL reconstruction. There is little quadriceps muscle strength loss after quadriceps harvest. A quadriceps tendon-patellar autograft is an adequate graft choice to ACL reconstruction.
\end{abstract}

\section{Introduction}

Anterior Cruciate ligament (ACL) reconstruction is among the most common orthopedic procedures, particularly among athletes. In addition to inherent decreases in the stability of the knee, ACL rupture can also lead to an increased risk for subsequent chondral or meniscal injury and diminished athletic performance. As a result, the optimal treatment of ACL injury has generated significant laboratory and clinical research [1].

Recent studies investigated the importance of different surgical techniques in consideration of the anatomy of the anterior cruciate ligament (ACL). Considering the anatomic insertion areas of the native ACL is the key to optimal results regarding biomechanical properties and resulting knee stability after ACL reconstruction. Anatomic ACL reconstruction is defined as reconstruction using the anatomic insertion area of both the tibial and femoral tunnels by respecting the anatomic origin of the ACL [2]. According to the literature, the femoral insertion has an oval shape and a mean diameter of 11-18 mm. The tibial insertion shows an oval, triangular shape with a mean diameter of 11-17 mm. From the origin of the lateral femoral condyle, the fibers of the ACL run obliquely to its insertion at the medial and lateral tibial spine and the area in between [3]. Graft choice for anterior cruciate ligament (ACL) reconstruction remains a controversial issue, but most surgeons are using autografts and, especially, the bone-patellar tendon-bone
(BPTB) graft and the hamstring tendon autograft (HTA). Donorsite morbidity from BPTB graft harvesting led to the use of other graft alternatives, such as the quadrupled hamstring tendons, the quadriceps tendon, and allografts [4].

The quadriceps tendon autograft (QTA) has been used with increasing frequency for both primary and revision ACL reconstruction [5]. The QTA has several advantages and disadvantages. The QTA is easy to harvest, can be obtained with or without a patellar bone block, and is adequately thick to accommodate an expanded tibial tunnel in revision operations [5]. A study has described early return of quadriceps function after ACL reconstruction with a QTA graft. The quadriceps graft can also be used in adolescents with open growth plates as it would not violate the tibial tubercle apophysis [6].

By moving the incision for graft harvest superior to the patella as in the quadriceps tendon graft harvest, the patient may no longer have to kneel directly on the scar. Also, an incision at the superior pole of the patella should not affect the saphenous nerve and will not affect the fat pad. Also, a smaller proportion of the extensor mechanism is disrupted, which could potentially prevent some of the extension weakness or extension loss noted in some studies evaluating patellar tendon [6]. Disadvantages of the QTA include the under-reported donor-site morbidity, the need to perform an additional skin incision, the lack of long- 


\section{Orthopedics and Rheumatology Open Access Journal (OROAJ)}

term clinical studies using this type of graft, and the scarcity of data regarding the biomechanical properties of the quadriceps tendon and its fixation methods [5].

It is clear, however, that this graft does have several advantages and is the favored autograft option for revision ACL surgery in the setting of well-placed but expanded sockets for which tunnel fill is critical [7].

\section{Materials and Methods}

\section{Patients}

Patient selection is based on a study of 20 patients with ACL tear who are candidates for arthroscopic reconstruction because of their high physical demands, aged 18-40 years old. Inclusion criteria includes Young and middle aged fit patients, clinically diagnosed as to have torn ACL, radiologically diagnosed as to have torn ACL. Exclusion criteria include Patients unfit for surgery, Diabetic patients. Patients with Joint arthritis \& Patients with multidirectional instability. Twenty patients with primary ACL insufficiency who met the inclusion criteria underwent Arthroscopic Anatomic ACL reconstruction using Quadriceps graft fixed with biodegradable interference screws. All patients were followed prospectively for a minimum of 12 months. Full history of the patients was collected including demographic characteristics (age, sex and occupation), mode of trauma, time from injury to surgery, side of injury and the level of physical activity before injury. Examination is done in collaboration with IKDC knee examination form. All patients had MRI examination to diagnose the torn ACL and any associated ligamentous injury. IKDC scoring system was applied to all patients before the surgery, 6 months post-operative and 1-year post-operative.

\section{Surgical technique}

The quadriceps tendon is harvested through a midline anterior, 3 to $5 \mathrm{~cm}$ long incision, starting at the proximal pole of the patella and extending proximally. Skin flaps are raised, the entire width of the quadriceps tendon is exposed, and the central 8 to $10 \mathrm{~cm}$ of the tendon is harvested without a patellar bone block. The skin incision can be easily mobilized to facilitate graft harvesting. The quadriceps tendon is very thick and usually it is not necessary to harvest the posterior leaf of it, thus sparing the vastus intermedius tendon. The harvested quadriceps tendon autograft is usually 8 to $9 \mathrm{~cm}$ long, $10 \mathrm{~mm}$ wide and $8 \mathrm{~mm}$ thick.

3-portal technique was used. The main anterolateral (AL) and anteromedial (AM) portals were created along the patellar tendon edges. The AL portal is created at the level of the inferior pole of the patella, allowing full visualization of the ACL tibial footprint from above. An accessory AM portal (AAM) located approximately $1 \mathrm{~cm}$ below and medial to the main AM portal, was finally created under direct visualization of the arthroscope with the help of a spinal needle (Figure 1).

The notch was debrided, saving 1 to $2 \mathrm{~mm}$ of ACL fibers at both the tibial and femoral footprint. The posterior edge of the lateral femoral condyle must be clearly identified. The medial aspect of the lateral femoral condyle contains the lateral intercondylar ridge (resident's ridge) representing the superior most boundary of the femoral ACL origin. The bifurcate ridge separates the AM and PL bundle origin. The remnants of the incompetent ACL were removed with thermo-cautery because arthroscopic shaving may inadvertently destroy the bony references. Attempts were made at preserving a small peripheral rim of ligament because these fibers are thought to contain proprioceptive elements.

The knee was flexed $120^{\circ}$ to make the resident's ridge horizontal in line with femoral shaft. Trying to feel the bifurcate ridge by probing, which is the landmark separating the native ACL bundles. If not felt, a point in the center of the femoral footprint was marked with a micro fracture needle taking in consideration the tunnel should be totally behind the lateral intercondylar ridge, typically in the lower one third of the lateral notch [8] (Figure 2).

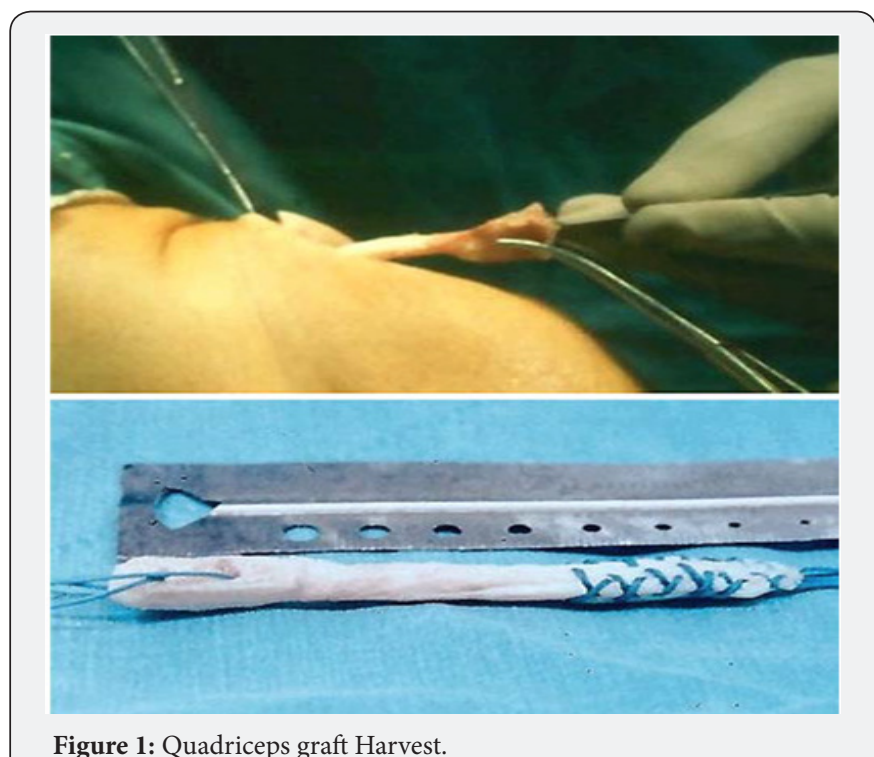

Figure 1: Quadriceps graft Harvest.

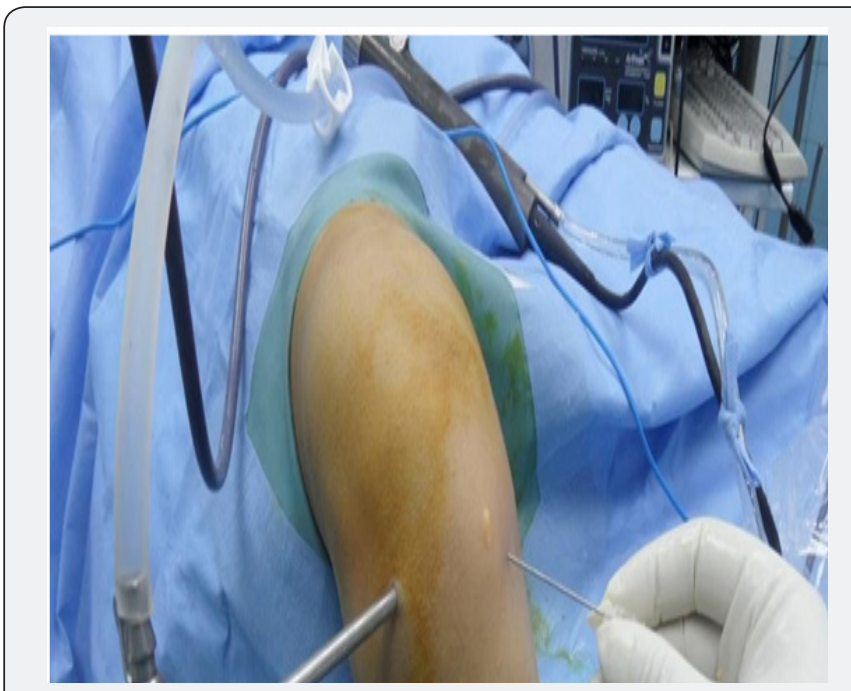

Figure 2: Accessory AM portal. 
A guide pin was drilled through the femur till it passes through the skin of the thigh and the leading end of the pin was held by an artery forceps. A rosette reamer according to the size of the graft was used to ream the femoral tunnel. Loop of vicryl No 2 wire was passed through the tunnel using a guide pin leaving the looped tip inside the knee.

The scope was introduced through the AL portal while the knee hanging free in $90^{\circ}$ flexion. The guide was set at $55^{\circ}$ angle. The guide aimer was passed through the AM portal. The tibial tunnel entrance was through the graft harvest incision, $1 \mathrm{~cm}$ medial to the tuberosity and about $3 \mathrm{~cm}$ distal to the tibial articular surface. The cannulated guide arm was passed to this point. Drilling a guide pin through the cannulated guide arm. After penetrating the joint, the guide was removed. Depending on the graft size, the tibial tunnel was reamed. A grasper was passed through the tibial tunnel to bring out the vicryl 2-0. The Ethibond no. 5 sutures of the prepared graft are passed using the vicryl 2-0 loop from the tibial tunnel to emerge outside the skin of the thigh.

By pulling on the Ethibond sutures outside the thigh, the graft is passed through the tibial then the femoral tunnel. The graft was kept under tension by holding the limb through pulling on the Ethibond sutures. Distal end of graft is fixed to femoral tunnel with interference screw, but proximal end of graft is fixed at the end of operation with interference screw. Arthroscopic assessment throughout full range of motion (ROM) to assess for impingement either on PCL or roof of the notch.

\section{Rehabilitation Guidelines}

The initial goal of rehabilitation is to reduce pain, inflammation and swelling, reestablish quadriceps control, and restore a normal gait. The operative knee is protected by a knee brace in the fully extended position for the first week, and full weight bearing is allowed. Quadriceps isometric exercises, a straight-leg raising exercise, and a passive range of motion start as early as possible. A series of closed kinetic-chain exercises are instructed. The range of motion should quickly recover to complete flexion and extension. Aggressive quadriceps and hamstring muscles strengthening exercises is initiated. Patients usually resume normal daily activities around 3 months after surgery, and typically return to sports activity after 6 months. Full recovery to pre-injury sports level can generally be achieved between 9 and 12 months following surgery.

\section{Results}

Table 1: IKDC score before operation, 6 months and 12 months after operation.

\begin{tabular}{|c|c|c|c|c|c|}
\hline & Mean & Standard Deviation & Median & Minimum & Maximum \\
\hline $\begin{array}{c}\text { Preoperative IKDC } \\
\text { score }\end{array}$ & 45.08 & 6.59 & 45.90 & 34.40 & 54.00 \\
\hline IKDC score at 6 m & 68.53 & 4.68 & 68.40 & 59.80 & 75.90 \\
\hline IKDC Score at 12m & 78.76 & 3.81 & 78.75 & 69.00 & 85.10 \\
\hline
\end{tabular}

\section{IKDC subjective knee evaluation}

It was assessed pre-operatively, 6 months and 12 months post-operatively. IKDC score before operation was 45.08 with a range from 34.40-54.00. IKDC score 6 months post-operative was 68.53 with a range from $59.80-75.90$. IKDC score 12 months post-operative was 78.76 with a range from 69.00-85.10 (Table 1).

\section{IKDC Score Correlations}

\section{Comparison over time}

Comparison between IKDC score over time period showing significant improvement over time from pre-operative ( $\mathrm{P}$ value $<0.001$ ), 6 months post-operative ( $\mathrm{P}$ value $<0.001$ ) to 12 months post-operative ( $\mathrm{P}$ value $<0.001$ ) (Table 2 ).

Table 2: Comparison between IKDC score before operation, 6 months and 12 months after operation.

\begin{tabular}{|c|c|c|c|c|c|c|}
\hline Mean & $\begin{array}{c}\text { Standard } \\
\text { Deviation }\end{array}$ & Median & Minimum & Maximum & P value \\
\hline $\begin{array}{c}\text { Preoperative IKDC } \\
\text { score }\end{array}$ & 45.08 & 6.59 & 45.90 & 34.40 & 54.00 & $<0.001$ \\
\hline IKDC score at $6 \mathrm{~m}$ & 68.53 & 4.68 & 68.40 & 59.80 & 85.90 \\
\hline IKDC Score at $12 \mathrm{~m}$ & 78.76 & 3.81 & 78.75 & 69.00 & 85.10 \\
\hline
\end{tabular}

\section{Correlations Between IKDC Score and Age (Table 3)}

\section{Correlations between IKDC score and side of injury}

Although the injury was more common in right knees more than the left, there is no significant difference in IKDC score between right and left knees pre-operatively, 6 months postoperatively and 12 months post-operatively (Table 4).

\section{Correlations between IKDC score and side of injury}

Although the injury was more common in right knees more than the left, there is no significant difference in IKDC score between right and left knees pre-operatively, 6 months postoperatively and 12 months post-operatively (Table 5). 


\section{Orthopedics and Rheumatology Open Access Journal (OROAJ)}

Table 3: Correlations between IKDC score and age.

\begin{tabular}{|c|c|c|c|c|}
\hline & & Preoperative IKDC score & IKDC score at 6m & IKDC Score at 12m \\
\hline \multirow{3}{*}{ Age } & Correlation Coefficient & $-.060-$ & .043 & $-.153-$ \\
\cline { 2 - 5 } & P value & .803 & .856 & .519 \\
\cline { 2 - 5 } & $\mathrm{N}$ & 20 & 20 & 20 \\
\hline
\end{tabular}

Table 4: Correlations between IKDC score and side of injury

\begin{tabular}{|c|c|c|c|c|c|c|c|c|c|c|c|}
\hline & \multicolumn{10}{|c|}{ Side of injury } & \multirow[t]{2}{*}{$P$ value } \\
\hline & \multicolumn{5}{|c|}{$\mathbf{L}$} & \multicolumn{5}{|c|}{$\mathbf{R}$} & \\
\hline & Mean & SD & Median & Minimum & Maximum & Mean & SD & Median & Minimum & Maximum & \\
\hline $\begin{array}{l}\text { Preoperative } \\
\text { IKDC score }\end{array}$ & 44.80 & 7.52 & 44.25 & 36.70 & 54.00 & 45.20 & 6.46 & 46.45 & 34.40 & 54.00 & 0.841 \\
\hline $\begin{array}{c}\text { IKDC score at } \\
6 \mathrm{~m}\end{array}$ & 68.80 & 3.75 & 69.00 & 64.40 & 73.60 & 68.41 & 5.16 & 68.40 & 59.80 & 75.90 & 0.968 \\
\hline $\begin{array}{c}\text { IKDC Score at } \\
12 \mathrm{~m}\end{array}$ & 78.37 & 3.79 & 78.75 & 71.30 & 81.60 & 78.93 & 3.94 & 78.75 & 69.00 & 85.10 & 0.841 \\
\hline
\end{tabular}

Table 5: Correlations between IKDC score and side of injury

\begin{tabular}{|c|c|c|c|c|c|c|c|c|c|c|c|}
\hline \multirow{2}{*}{} & \multicolumn{9}{c|}{ Side of injury } & P value \\
\cline { 2 - 14 } & \multicolumn{9}{|c|}{ L } & \multicolumn{9}{c|}{ R } \\
\cline { 2 - 14 } & Mean & SD & Median & Minimum & Maximum & Mean & SD & Median & Minimum & Maximum \\
\hline $\begin{array}{c}\text { Preoperative } \\
\text { IKDC score }\end{array}$ & 44.80 & 7.52 & 44.25 & 36.70 & 54.00 & 45.20 & 6.46 & 46.45 & 34.40 & 54.00 & 0.841 \\
\hline $\begin{array}{c}\text { IKDC score } \\
\text { at 6m }\end{array}$ & 68.80 & 3.75 & 69.00 & 64.40 & 73.60 & 68.41 & 5.16 & 68.40 & 59.80 & 75.90 & 0.968 \\
\hline $\begin{array}{c}\text { IKDC Score at } \\
12 \mathrm{~m}\end{array}$ & 78.37 & 3.79 & 78.75 & 71.30 & 81.60 & 78.93 & 3.94 & 78.75 & 69.00 & 85.10 & 0.841 \\
\hline
\end{tabular}

\section{Discussion}

Successful management of anterior cruciate ligament (ACL) deficiency is essential to prevent instability, risk of meniscal injury, and premature osteoarthritis [9]. Arthroscopic ACL reconstruction techniques are still evolving. Recently, the focus of ACL reconstruction has been anatomic reconstruction, which can be defined as placement of tunnels in the center of the native ACL insertion sites on the tibia and femur using either single or double-bundle techniques [9]. Anatomic ACL reconstruction requires the accurate identification of the anatomy of the ACL and an attempt to reproduce normal graft forces by placing the graft in the center of the anatomic footprint and to apply appropriate tension to mimic the native ACL [9].

With these essential principles in mind, it is thus important to identify specific landmarks that will assist the surgeon in anatomic reconstruction. Some authors propose using the lateral intercondylar and bifurcate ridges to locate the native ACL femoral insertion site. These bony landmarks have been shown to be accurate, 14 but the bifurcate ridge can be absent in $12 \%$ to $52 \%$ of cases [10]. Autografts, allografts and synthetic grafts have all been used. Allografts (commonly patella, Achilles or tibialis anterior or posterior tendons) and synthetic grafts avoid donor site morbidity but have several disadvantages including lower stability and higher failure rates, higher risk of infection and disease transmission, possible immunological reaction and increased cost. For these reasons, most surgeons favor routine autograft use [11].

The use of quadriceps tendon autograft in anterior cruciate ligament (ACL) reconstruction was first described by Marshall et al. [1] but it has not gained widespread use like other autograft options. Many surgeons traditionally have limited its use to select cases such as revisions. Recently, however, there has been increased interest in the quadriceps graft, possibly because of the recent body of evidence in support of autograft use for ACL reconstruction in younger patients and contact athletes [12].

The quadriceps tendon autograft offers several advantages. It contains a denser collagen matrix compared with a patellar tendon graft of the same thickness, with less interstitial tissue and $20 \%$ more collagen per unit Volume [12]. The typical graft diameter is $10 \mathrm{~mm}$; hamstring autografts narrower than 8.0 $\mathrm{mm}$ have recently been implicated in higher failure rates. The quadriceps tendon autograft is also usually still available in the revision setting, and recent evidence has suggested improved graft survivorship when autografts are used for these patients [13]. 


\section{Orthopedics and Rheumatology Open Access Journal (OROAJ)}

In addition, the quadriceps autograft avoids some of the morbidity of other graft options, with less reported anterior knee pain and numbness compared with patellar tendon bone graft, as well as none of the residual cramping that can occur with hamstring tendon harvest.

\section{References}

1. Fu FH, Karlsson JA (2010) long journey to be anatomic. Knee Surg Sports Traumatol Arthrosc 18(9): 1151-1153.

2. Zantop T, Petersen W, Fu FH (2005) Anatomy of the anterior cruciate ligament. Oper Tech Orthop 15(1): 20-28.

3. Petersen W, Zantop T (2007) Anatomy of the anterior cruciate ligament with regard to its two bundles. Clin Orthop Relat Res 454(454): 35-47.

4. Farrow LD, Chen MR, Cooperman DR, Victoroff BN, Goodfellow DB (2007) Morphology of the Femoral Intercondylar Notch. JBJS 89(10): 2150-2155

5. Dienst M, Burks RT, Greis PE (2002) Anatomy and biomechanics of the anterior cruciate ligament. Orthop Clin North Am 33(4): 605-620.

6. Siebold Rainer (2014) Anterior Cruciate Ligament Reconstruction 3: 156

7. Hunter, Robert E, Nicholas A Sgaglione (2010) AANA Advanced Arthroscopy Series: The Knee. In: Richard KN Ryu (Ed.), Elsevier Inc pp. 178-190.
8. Pansard E, Klouche S, Vardi G, Greeff E, Hardy P, et al. (2015) How accurate are anatomic landmarks for femoral tunnel positioning in anterior cruciate ligament reconstruction? An in vivo imaging analysis comparing both anteromedial portal and outside-in techniques. Arthroscopy 31(5): 882-889.

9. Bird JH, Carmont MR, Dhillon M, Smith N, Brown C, et al. (2011) Validation of a new technique to determine midbundle femoral tunnel position in anterior cruciate ligament reconstruction using 3-dimensional computed tomography analysis. Arthroscopy 27(9): 1259-1267.

10. Mulford JS, Hutchinson SE, Hang JR (2013) Outcomes for primary anterior cruciate reconstruction with the quadriceps autograft: A systematic review. Knee Surgery, Sport Traumatol Arthrosc 21(8): $1882-1888$

11. Grob K, Manestar M, Filgueira L, Ackland T, Gilbey H, et al. (2016) New insight in the architecture of the quadriceps tendon. J Exp Orthop 3(1): 32 .

12. Wright RW, Huston LJ, Haas AK, Spindler KP, Nwosu SK, et al. (2014) Effect of graft choice on the outcome of revision anterior cruciate ligament reconstruction in the Multicenter ACL Revision Study (MARS) Cohort. Am J Sports Med 42(10): 2301-2310.

13. Joseph P DeAngelis, Fulkerson JP (2007) Quadriceps tendon A reliable alternative for reconstruction of the anterior cruciate ligament. Clin Sports Med 26(4): 587-596.

\section{Your next submission with Juniper Publishers} will reach you the below assets

- Quality Editorial service

- Swift Peer Review

- Reprints availability

- E-prints Service

- Manuscript Podcast for convenient understanding

- Global attainment for your research

- Manuscript accessibility in different formats

( Pdf, E-pub, Full Text, Audio)

- Unceasing customer service

Track the below URL for one-step submission https://juniperpublishers.com/online-submission.php 